\title{
DIAGNÓSTICO E PLANO DE MARKETING PARA UMA EMPRESA DE NORMALIZAÇÃO DE TRABALHOS ACADÊMICOS
}

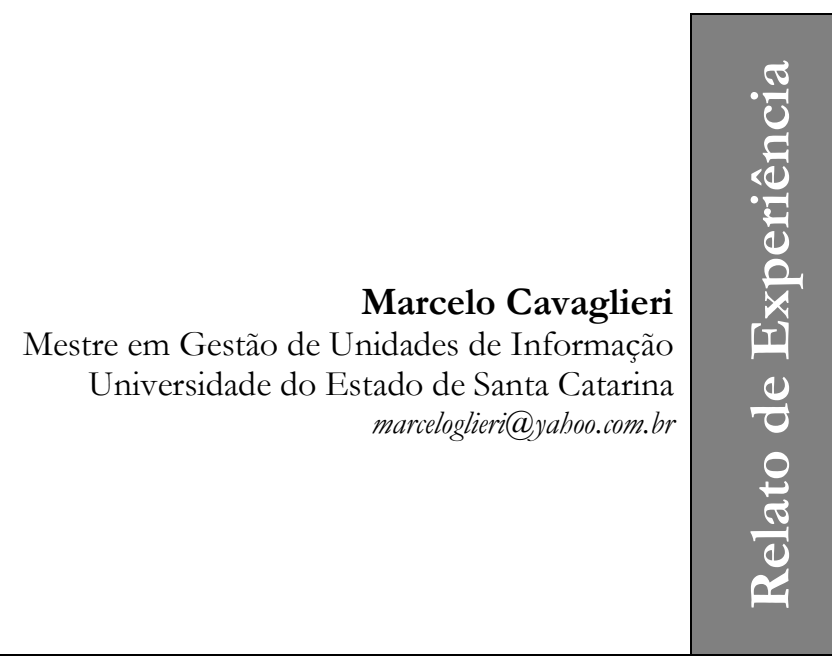

\section{Resumo}

O mercado de prestação de serviço na área de normalização de trabalhos acadêmicos ainda é pouco conhecido, com poucas empresas e pessoas especializadas na área. Porém, nos últimos anos, com mais acadêmicos ingressando no ensino superior e a falta de tempo para dedicação a esta atividade, a busca por este tipo de serviço aumentou. Neste cenário, é essencial traçar estratégias de marketing com a finalidade de tornar a empresa conhecida e ser uma opção de contratação de clientes. O estudo foi desenvolvido na empresa MC Normalizações, prestadora de serviços de formatação e normalização de trabalhos acadêmicos de acordo com as normas da ABNT. Foi elaborado um plano de marketing com intuído de ampliar sua participação no mercado, podendo, assim, fidelizar novos clientes. Para conhecer os clientes em potencial, realizou-se um questionário para identificar as principais necessidades e a disposição financeira para bancar este tipo de serviço. Foi possível diagnosticar que a empresa não possui um departamento de marketing consolidado, mas pratica algumas ações de marketing junto aos clientes. Este plano de marketing servirá de base para que as novas ações, aqui propostas, possam ajudar a empresa a atingir sua missão e visão. Diante dos resultados apresentados, pode-se concluir que o foco das ações de marketing deve estar voltado à divulgação via Internet, pois é onde os clientes mais procuram este serviço, e pautadas na qualidade, que irá ajudar na divulgação diante de colegas de faculdade e amigos.

\section{Palavras-chave}

Plano de marketing. Trabalhos acadêmicos. ABNT. Gestão da informação - marketing.

\section{INTRODUÇÃO}

A expansão dos mercados e o aumento da concorrência fazem com que as empresas tenham cada vez mais a necessidade de se aprimorar e buscar alternativas para atrair novos clientes e fidelizar os já existentes. A oferta cada vez maior de produtos e serviços fez com que os clientes passassem a ter um nível maior de exigência e exigiu que muitas empresas melhorassem a qualidade de seus produtos, investindo ainda mais no marketing para atrair novos clientes.
Para atender às exigências do mercado e se manter competitivo frente à concorrência, as empresas necessitam trabalhar baseadas em estratégias que possibilitem uma visão de futuro. Estas estratégias devem auxiliar no estabelecimento de metas e objetivos capazes de atingir as expectativas atuais e futuras dos clientes. A pesquisa de clientela é uma boa ferramenta para conhecer o mercado, assim como as necessidades dos clientes e os pontos que podem ser explorados para atingir determinado público. Neste sentido, o objetivo deste trabalho é desenvolver um plano de marketing para a MC Normali- 
zações, a fim de atrair novos clientes e fidelizar os existentes por meio de uma pesquisa de mercado. Tal pesquisa objetiva auxiliar no desenvolvimento de novas estratégias de marketing.

A MC Normalizações, criada em 12 de agosto de 2007, é uma empresa movida pelo desejo de oferecer um serviço padronizado de qualidade na normalização de trabalhos acadêmicos e na área de consultoria. Prima pela qualidade no que faz, uma vez que seus clientes são os grandes divulgadores desse trabalho.

A metodologia utilizada para alcançar o objetivo foi uma pesquisa predominantemente qualitativa com o objetivo de possibilitar uma dimensão mais abrangente no sentido de conhecer o mercado de trabalho em que a MC Normalizações está inserida. Devido à necessidade de se conhecer alguns aspectos relacionados ao marketing, o estudo também é classificado como exploratório e descritivo. $\mathrm{O}$ instrumento de coleta de dados foi um questionário, aplicado em janeiro de 2017, com clientes em potencial, por meio da ferramenta Google Docs.

O desenvolvimento do plano de marketing proposto almeja auxiliar a organização de forma que esta acompanhe as novas tendências do mercado em que está inserida, bem como aumente sua participação no mercado e, consequentemente, suas vendas, fidelizando novos clientes. Estar preparada para as mudanças do mercado e do avanço de novas tecnologias é fundamental para seu crescimento e permanências no mercado atual.

Para tanto o presente trabalho está estruturado da seguinte forma: na seção 2 é apresentado o desenvolvimento do trabalho, com conceitos de marketing e o composto de marketing que envolve uma empresa. Tal discussão serve para dar maior embasamento teórico a respeito da discussão central que é desenvolver novas estratégias de marketing para MC Normalizações. Na seção 3, são descritos os resultados da pesquisa mercadológica abordando primeiro os aspectos relacionados ao perfil do cliente, bem como suas necessidades inerentes ao serviço de normalização de trabalhos acadêmicos. Em seguida é apresentado o plano de marketing. $\mathrm{Na}$ seção 4, são apresentadas as considerações finais do trabalho.

\section{MARKETING E O COMPOSTO DE MARKETING (4 Ps)}

As relações de troca estabelecidas pela humanidade existem desde a antiguidade. Ao longo do tempo, foram surgindo sistemas de medidas para que as mercadorias vendidas pudessem ter o seu valor comercial. Com a evolução da sociedade e o crescimento do comércio nas últimas décadas, tais fenômenos ficaram mais evidentes e passaram a ter uma nova sistematização e denominação que vem ganhando espaço dia a dia.

Esta sistematização está relacionada ao marketing, que vem ganhando importância como uma ferramenta estratégica para as empresas. Assim, torna-se essencial abordar conceitos e o plano de marketing.

O marketing vem sendo discutido há muito tempo, porém, muitas empresas ainda não compreenderam seu real valor no mundo moderno. Kotler (2000, p. 27) explica que o marketing é

[...] um processo social e gerencial pelo qual indivíduos e grupos obtêm aquilo que necessitam e desejam através da criação, oferta e troca de produtos de valor com outros.

Las Casas (2009, p. 15) amplia o conceito, destacando que:

\footnotetext{
Marketing é a área do conhecimento que engloba todas as atividades concernentes às relações de trocas orientadas para a criação de valor dos consumidores, visando alcançar determinados objetivos de empresas ou indivíduos através de relacionamentos estáveis e considerando sempre o meio ambiente de atuação e o impacto que essas relações causam no bem-estar da sociedade.
}

A última definição de marketing, anunciada pela Associação Americana de Marketing (AMA) e aprovada em julho de 2013, descreveu o marketing da seguinte forma: 
O marketing é a atividade, conjunto de instituições e processos para criar, comunicar, entregar e trocar ofertas que tenham valor para consumidores, clientes, parceiros e a sociedade em geral. (AMA, 2013, tradução nossa).

Tendo em vista tais definições, as empresas devem descobrir o que o cliente deseja e adaptar seus produtos às necessidades dos mesmos. Isto deve ser feito de modo que o composto mercadológico seja focado nestas necessidades, a fim de gerar maiores benefícios para ambas as partes. As empresas de pequeno porte precisam acompanhar a acirrada mudança no mercado atual por meio de inovações. Os dados do SEBRAE (2016) mostram que nos últimos anos as microempresas (ME) possuem uma taxa de mortalidade superior a $50 \%$ em dois anos de existência. Isso se deve ao fato de não acompanharem as novas tendências do mercado e as novas necessidades de seus clientes.

Para Dias (2007), o desempenho do marketing na organização ajuda as empresas a se manterem no mercado. Isto ocorre, pois, o marketing auxilia nas tomadas de decisões, na gestão de recursos, na coordenação dos processos, na avaliação das áreas de responsabilidade da empresa, ou seja, na análise, no planejamento, na implementação e no controle das estratégias.

Sob o ponto de vista da colocação dos autores citados, entende-se que qualquer empresa precisa do marketing, pois fornece valor ao cliente, ajudando a satisfazer suas necessidades e expectativas.

\subsection{Composto de Marketing}

Para o direcionamento de uma boa estratégia de marketing e para que ela interaja com a organização como um todo, se faz necessário o conhecimento do composto de marketing, para, então, alcançar o comprometimento necessário para seu sucesso.

O mix de marketing (composto de marketing) é um conjunto de diversas ferramentas destinadas à satisfação do cliente. Mediante estas ferramentas, pretende-se desenvolver o produto, estabelecer preço, escolher os canais de distribuição e as técni- cas de comunicação mais adequadas para apresentar um produto que realmente satisfaça as necessidades dos clientes e são utilizadas pelos profissionais de marketing para obter as respostas desejadas de seus mercados-alvo (KOTLER, 2000).

Em consonância, Chiavenato (2005) descreve que o composto de marketing faz parte dos objetivos estratégicos e específicos do marketing, fazendo com que a empresa conheça o mercado em que ela está inserida e definindo um composto de atividades ligadas ao produto, ao preço, à promoção, à propaganda, à distribuição e à venda.

Além da abordagem tradicional do composto de marketing, denominada 4 Ps, existem mais 4Ps que estão relacionados aos serviços. De acordo com Lovelock e Wright (2001, p. 21),

A natureza dos serviços, que envolve aspectos como envolvimento com o cliente na produção e importação do fator tempo, exige a inclusão de outros elementos estratégicos: evidências físicas, processos, pessoas e produtividade e qualidade.

Assim, para ter um maior entendimento do composto de marketing, nas subseções abaixo apresentam-se seus elementos.

Para que exista uma organização é necessário que haja o produto, seja ele tangível ou não. O produto é o eixo central e, em conjunto com ele, a organização apresenta e planeja as estratégias das outras ferramentas do composto. Estas devem estar diretamente ligadas ao produto e se ajustarem a ele. $\mathrm{O}$ produto pode ser definido como um conjunto de atributos físicos, psicológicos, ou de utilidade, assim como atributos simbólicos que, no todo, trazem alguma satisfação ou benefícios a seu consumidor (KEEGAN; GREEN, 2003).

De forma geral, produtos e serviços tem a mesma finalidade. Isto é, satisfazem o desejo ou a necessidade dos clientes, gerando satisfação e valor. No caso de serviços, é fortemente demarcado o componente intangível. Assim, os serviços são experiências que geram valor, podendo ser maiores ou menores seus componentes tangíveis (ASSIS, 2001). 
O produto ou serviço é o principal fator que pode gerar a satisfação do consumidor, pois vai suprir uma carência do cliente, de modo que os outros componentes do composto de marketing estão intrinsecamente ligados e relacionados a ele.

Outro elemento do composto de marketing é o preço, ao qual entende-se que está diretamente relacionado com a estimativa de valor do consumidor após a compra, considerando os benefícios que o produto lhe forneceu. É preciso levar em consideração os preços dos concorrentes e outros fatores externos e internos para encontrar o melhor preço dos produtos ou serviços oferecidos.

Para Churchill e Peter (2005, p. 314) "preço é quantidade de dinheiro, bens ou serviços que deve ser dada para se adquirir à propriedade ou uso de um produto". Kotler e Keller (2005) destacam que dentre os elementos do mix de marketing, o preço é o único que produz receitas, enquanto os demais produzem custos. O preço tem uma flexibilidade mais elevada quando comparado aos outros componentes do mix. O preço também tem a função de informar ao mercado sobre o posicionamento do valor desejado pela empresa para seu produto ou marca. Quando bem trabalhado, um produto agrega mais valores e com isso pode ser comercializado a um preço superior, agregando maior valor para a empresa.

Para garantir satisfação do cliente, é preciso acertar na relação custo benefício ou preço/qualidade. O cliente quer ficar satisfeito com o que foi servido e achar justo o total cobrado. Ao pagar a conta, deve sentir que valeu a pena a escolha e recebeu mais valor do que poderia obter dos concorrentes. Com isso, retornará ao estabelecimento e o indicará aos amigos (MARICATO, 2005).

Para que um produto tenha boas vendas é necessário que o consumidor possa visualizar esta mercadoria, ou seja, que o produto esteja acessível e disponível ao público alvo. Sendo assim, pode-se afirmar que o ambiente e a localização em que o produto está ofertado são fatores preponderantes para a escolha do consumidor.
Para Kotler (2000, p. 37), "praça é formada pelo ambiente de atuação, canais de distribuição e clientes-alvo aos quais a organização pretende atender". Em consonância, Westwood (2007) descreve que a "praça" e a "promoção" dizem respeito a atingir seus clientes potenciais em primeiro lugar, e o "produto" e o "preço" permitem que você satisfaça as necessidades deles.

Com um bom marketing é possível atingir clientes de variadas localidades sem depender apenas do ponto de venda onde está localizado, principalmente na prestação de serviços, uma vez que a Internet rompeu fronteiras e as empresas estão conseguindo ir cada vez mais longe, oferecendo seus serviços e galgando novos clientes.

O último elemento é a promoção, que, para Kotler e Armstrong (2003, p. 315),

[...] pode ser entendida como a comunicação de marketing, composta por quatro ferramentas principais que são a propaganda, a venda pessoal, a promoção de vendas e as relações públicas.

Na visão de Las Casas (2006, p. 240), "promoção é o significado de comunicação". Deste modo, para a empresa se comunicar com seus consumidores, o empreendedor terá que pensar no composto promocional alcançando assim como no objetivo da comunicação. O composto promocional é uma relação dos tipos de promoções que a empresa faz num determinado período, utilizando estratégias de promoção.

Para Churchill Júnior (2005, p. 166), a estratégia de promoção pode influenciar os consumidores em todos os estágios do processo de compra, onde

$$
\begin{aligned}
& \text { [...] suas mensagens podem lembrar } \\
& \text { aos consumidores que eles têm um } \\
& \text { problema, que o produto pode resolver } \\
& \text { o problema e que ele entrega um valor } \\
& \text { maior do que os produtos concorren- } \\
& \text { tes. }
\end{aligned}
$$

Com entendimento teórico do mix de marketing, é possível visualizar melhor os pontos que devem ser trabalhados no plano de marketing, de modo que sua construção possa ser eficiente e servir de aporte na melhoria da empresa. 


\section{ANÁLISE MERCALOGÓGICA E PLANO DE MARKETING PARA MC NORMALIZAÇÕES}

O plano de marketing apresentado, contempla a formalização da ação, ou seja, trata-se de um manual de implementação, avaliação e controle de indicadores para a empresa, que deve estar minunciosamente atrelados aos objetivos estratégicos da mesma.

\subsection{Análise mercadológica}

A análise mercadológica deve ser uma das primeiras atitudes dos empreendedores para abertura ou expansão de um novo negócio. Fornece dados essenciais para auxiliar o investidor na tomada de decisão. Neste cenário, o número de matrículas no ensino superior cresceu $81 \%$ em dez anos. Entre 2003 e 2012, o número cresceu de 3,8 milhões para 7 milhões (MORENO; FAJARDO, 2013). Com a entrada crescente de pessoas nas universidades, a procura pelo serviço de formatação e normalização também aumenta. Porém, os profissionais especializados em biblioteconomia que podem prestar este tipo de trabalho ainda representam pequena parte desse número e não cresce na mesma proporção.

O setor está em alta, pois o número de Universidades está crescendo e com isso mais pessoas têm a oportunidade de cursar uma faculdade. A autora Griesinger (2015) destaca em seu artigo uma pesquisa do Instituto Brasileiro de Geografia e Estatística (IBGE), que enfatiza o contexto favorável à ampliação do ensino superior no Brasil. Tais consequências se dão principalmente pelo aumento do nível educacional da população e pelas melhorias nas condições econômicas das famílias. Os jovens de hoje, ao contrário do contexto histórico do país, seguem estudando, em vez de se dedicarem exclusivamente ao trabalho. Tais medidas, juntamente com a expansão da educação a distância, geram um ambiente favorável para pessoas de qualquer faixa etária ingressarem na faculdade.
O posicionamento da MC Normalizações é feito por diferenciação, já que a empresa pretende se destacar entre seus concorrentes. O destaque visado ocorre, principalmente, no tempo de entrega e confiabilidade na segurança da informação, agregando valor aos serviços prestados.

É fundamental buscar o melhor posicionamento estratégico perante o ambiente que a empresa está inserida, pois ele irá dimensionar todo o planejamento de marketing. $\mathrm{O}$ posicionamento está relacionado à percepção que os clientes têm de seu produto e, portanto, o desafio está em como posicionar o produto de forma que o cliente o observe como a solução dos problemas, o atendimento das necessidades e a realização de seus objetivos.

Para que ações possam ser tomadas, a fim de alavancar novos clientes e fidelizar os existentes, é necessário conhecer o mercado, a necessidade dos clientes e a melhor forma de satisfazer suas expectativas. Neste sentido, foi realizada uma pesquisa com a finalidade de conhecer essas premissas e viabilizar propostas de ação a serem implementadas.

A pesquisa com clientes em potencial da MC Normalizações foi feita em janeiro de 2017 e enviada por e-mail por meio da ferramenta Google Docs. Obteve-se o retorno de 102 pessoas de graus de instruções variados, porém, a sua maioria em nível de graduação e pós-graduação. A escolha dos pesquisados se deu de forma aleatória nos quatro municípios principais que compõem a grande Florianópolis (Florianópolis, São José, Palhoça e Biguaçu). Foi verificado que $40 \%$ dos respondentes são homens e $60 \%$ são mulheres, expondo a realidade brasileira de que a maioria dos acadêmicos são do sexo feminino, que representa $60 \%$ dos acadêmicos concluintes (BRASIL, 2015). Tais dados são importantes na formulação de estratégias, que podem ser voltadas para o público feminino, tendo em vista maior representatividade.

Quanto ao perfil de idade da maioria dos respondentes $(50,49 \%)$ está entre a faixa de 31 a 50 anos, seguida da faixa de 21 a 30 $(42,41 \%)$. Com estes dados é possível co- 
nhecer melhor a maturidade do cliente, para assim focar em ações voltadas para este público. Zuini (2011) enfatiza que para atrair o consumo do público jovem é necessário aceitar a diversidade e reconhecer a pluralidade do jovem de hoje, que consegue ter vários focos sem que isso tenha um efeito paralisante, mas, sim, transformador. Saraiva (2012, p. 1) complementa afirmando que

Conquistar o jovem é fundamental em uma empresa que se mantém a anos no mercado, porque depois que ele cresce, vai levar seus filhos e família para frequentar aquele estabelecimento também.

No total de pesquisados, $83,8 \%$ possuem conhecimento das normas da Associação Brasileira de Normas Técnicas (ABNT), que padronizam o formato e a normalização dos trabalhos acadêmicos, mas, por outro lado, 67,66\% deles dizem não dispor de tempo para realização dessa atividade. Esse último dado mostra que uma empresa que forneça este tipo de serviço terá mercado. Pois, se as pessoas reconhecem que não têm conhecimento técnico, em algum momento buscarão profissionais especializados que ofereçam suporte necessário na prestação deste serviço. Las Casas (2011) preconiza que a aplicação do marketing exige que os produtos sejam vendidos para quem deles necessita. Neste caso, temos uma grande necessidade de consumo que representa um potencial muito favorável na criação da MC Normalizações.

A maioria das pessoas estariam dispostas a pagar um profissional que normalizasse seu Trabalho de Conclusão de Curso (TCC). Com 70\% das pessoas dispostas a pagar por este trabalho, a empresa precisa apenas dar as condições de pagamento e um preço justo, que terá muitos trabalhos para captar. Com os $30 \%$, pode-se fazer campanhas de conscientização que despertem o seu interesse e que viabilizem financeiramente o trabalho. O Gráfico 1 mostra que a maioria dos pesquisados estariam dispostos a pagar o mínimo que foi estipulado na pesquisa.

\section{Gráfico 1 - Disponibilidade de valor a pagar pela formatação e normalização}

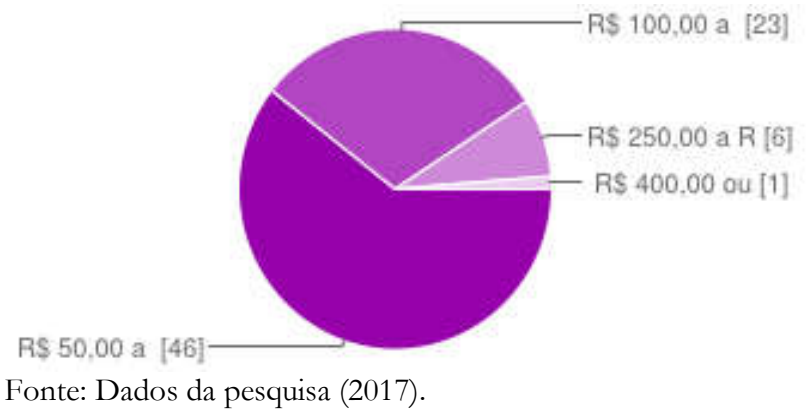

$\mathrm{R} \$ 50,00$ a $\mathrm{R} \$ 100,00$

$46-61 \%$

$\mathrm{R} \$ 100,00$ a $\mathrm{R} \$ 250,00$

$23-30 \%$

$\mathrm{R} \$ 250,00$ a $\mathrm{R} \$ 400,00$

$6-8 \%$

$\mathrm{R} \$ 400,00$ ou mais.

$1-1 \%$
Muitas também desconhecem a complexidade do trabalho e que existem profissionais especializados que desenvolvem este serviço. Porém, com esta pesquisa é possível desenvolver trabalhos para este público que está disposto a pagar o mínimo possível ou também desenvolver ações de publicidade de forma a alcançar um público que esteja disposto a investir mais na qualidade de seu trabalho. Neste sentido, Las Casas (2011) aconselha que é preciso tomar muito cuidado para não vender produtos e serviços para quem não tem condições de pagar; deste modo, é preciso saber ao máximo o perfil dos clientes, para poder estipular o valor do serviço que será oferecido. Com tais cuidados, pode-se evitar aborrecimentos de cobranças por parte do vendedor e insatisfação por não poder cumprir com o compromisso por parte do cliente. 
Gráfico 2 - Renda bruta dos clientes potenciais da MC Normalizações

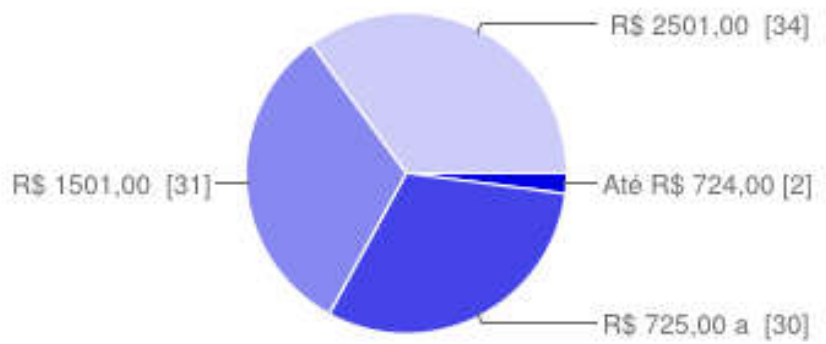

Até $\mathrm{R} \$ 724,00$.

$\mathrm{R} \$ 725,00$ a $\mathrm{R} \$ 1500,00$

$\mathrm{R} \$ 1501,00$ a $\mathrm{R} \$ 2500,00$

$\mathrm{R} \$ 2501,00$ ou mais.
$2-2 \%$

$30-31 \%$

$31-32 \%$

$34-35 \%$

Fonte: Dados primários, 2017.

No resultado expresso no Gráfico 2, observa-se um equilíbrio entre a renda das pessoas pesquisadas, sendo que $33 \%$ ganham até 1500 reais, $32 \%$ de 1501 a 2500 reais e o restante acima de 2501 reais. Considera-se um potencial aquisitivo bom, indicando que teriam condições de pagar por um serviço de boa qualidade. Com este resultado é possível perceber, que, apesar das pessoas estarem dispostas a pagar o mínimo possível estipulado no Gráfico 1, possuem uma renda razoavelmente alta. Diante de tais evidências, é possível ter ações mostrando a complexidade do serviço e a exigência de ter profissionais qualificados envolvidos na prestação deste trabalho, assim, possivelmente as pessoas iriam se dispor a pagar uma quantia maior para ter seu trabalho reconhecido pela excelência.

Os resultados expressam que 91\% dos respondentes não conhece nenhuma empresa que trabalhe com as normas da ABNT. Isso demonstra grande potencial para criação da MC Normalizações, pois pode atingir um público que até o momento tem desconhecimento de empresas prestadoras deste tipo de serviço. Tal resposta justifica a criação deste plano de marketing, com a proposta de ações concretas que possam dar maior visibilidade a empresa estudada, de modo a torná-la conhecida no ramo de prestação de serviços relacionados à ABNT. Santana (2001) esclarece que uma das formas de tornar a empresa conhecida é consolidando sua marca, pois ela é o grande patrimônio da empresa, cuja personalidade ganha força com o passar do tempo, pela atuação, filosofia e política de negócios.

A autora Sueli do Amaral (2011, p. 85) enfatiza que para tornar conhecida uma empresa na área da ciência da informação é fundamental trabalhar o marketing da informação

[...] para evidenciar os benefícios da apropriação conceitual do marketing nesta área do conhecimento e dar visibilidade ao papel desempenhado pelas unidades e profissionais da informação como agentes sociais capazes de contribuir para o desenvolvimento da sociedade.

Gráfico 3 - Local de busca por uma empresa de normalização de trabalhos acadêmicos

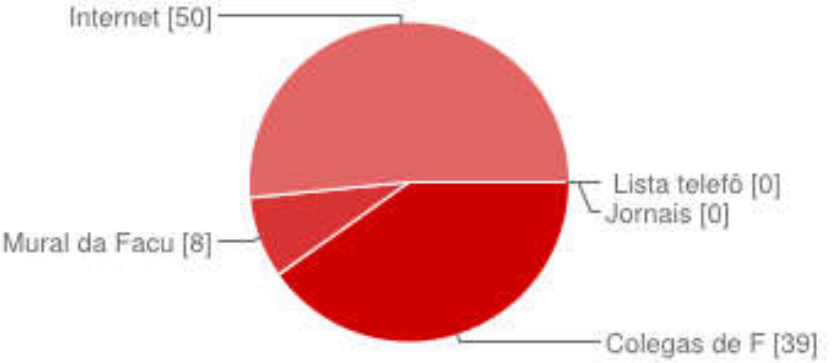

Colegas de Faculdade

$39-40 \%$

Mural da Faculdade

$8-8 \%$

Internet

$50-52 \%$

Lista telefônica

0 - $-0 \%$

Jornais

0 - $0 \%$

Fonte: Dados da pesquisa (2017). 
No Gráfico 3, percebe-se que, na busca por uma empresa prestadora de serviços de $\mathrm{ABNT}, 50 \%$ dos respondentes a faria pela Internet e 40\% buscariam uma indicação com colegas de faculdade. Esta pergunta foi direcionada para que a empresa identifique onde deve focar suas ações de marketing e direcionar seu investimento. Pode-se constatar que, apesar da indicação dos colegas ser fundamental, é preciso desenvolver um bom trabalho de divulgação na Internet, para que a empresa fique conhecida e possa gerar mais indicações por parte de colegas de estudo.

Com o avanço da Internet, os consumidores passaram a adquirir seus produtos em suas próprias residências, conforme expõe Dias (2016, p. 1), alegando que

\begin{abstract}
A Internet mudou significativamente a forma como as pessoas adquirem um produto ou serviço, pois a regra não é mais como encontrar seus clientes, mas sim como ser encontrado por eles de forma pouco invasiva e com credibilidade.
\end{abstract}

Como a MC normalizações não precisa da presença física do cliente para realizar o serviço, a Internet se torna o principal trunfo de divulgação para captação dos clientes, pois possibilita atender clientes de todos os lugares do Brasil e exterior.

Gráfico 4 - Elemento importante na busca de uma empresa de formatação de trabalhos acadêmicos

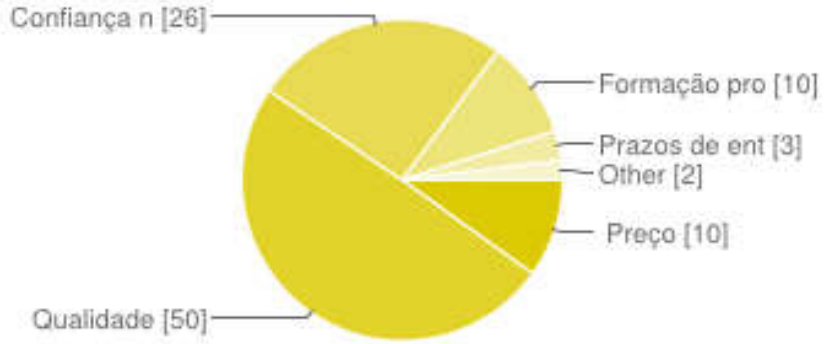

Fonte: Dados da pesquisa (2017).

O Gráfico 4 mostra que a qualidade é a parte mais importante na busca pelos serviços da ABNT, seguido pela confiança na empresa. Este resultado firma as competências que a empresa deve desenvolver no decorrer de seu trabalho para buscar mais clientes e garantir a satisfação dos mesmos. A qualidade na prestação de um serviço deve iniciar com uma boa qualificação dos profis-

$\begin{array}{lc}\text { Preço } & \mathbf{1 0}-\mathbf{1 0} \% \\ \text { Qualidade } & \mathbf{5 0 - 5 0 \%} \\ \text { Confiança na empresa } & \mathbf{2 6 - 2 6 \%} \\ \text { Formação profissional } & \mathbf{1 0 - 1 0 \%} \\ \text { Prazos de entrega } & \mathbf{3}-3 \% \\ \text { Outros } & \mathbf{2}-2 \%\end{array}$

sionais, pois a gestão de qualidade é um fator crucial para o sucesso de qualquer empreendimento. Longenecker et al. (2015) avaliam que a qualidade deve ser usada como uma ferramenta competitiva e que o esforço da empresa deve começar com o foco no cliente que compra os produtos ou serviços da organização. Sem isso, a busca pela qualidade se degenera com facilidade.

Gráfico 5 - Frequência com que os clientes utilizam ou pretendem utilizar os serviços de formatação e normalização

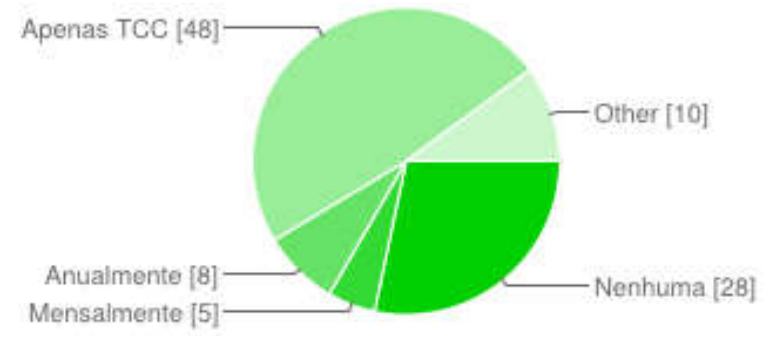

$\begin{array}{lr}\text { Nenhuma } & \mathbf{2 8}-28 \% \\ \text { Mensalmente } & \mathbf{5}-5 \% \\ \text { Anualmente } & \mathbf{8}-8 \% \\ \text { Apenas TCC } & \mathbf{4 8}-48 \% \\ \text { Outros } & \mathbf{1 0}-10 \%\end{array}$

Fonte: Dados primários, 2017. 
No Gráfico 5, evidencia-se que a maioria das pessoas pretendem utilizar os serviços apenas em seu TCC. Porém, com o aumento de pessoas ingressando nas faculdades, o número de clientes em potencial tende a crescer também. Em consonância, mesmo que este cliente não volte a precisar dos serviços, ele pode indicar a empresa para seus colegas, conforme visto no Gráfico 3, onde $40 \%$ buscam indicações de colegas. Para isso, é fundamental um atendimento e serviço de qualidade para que esse cliente possa trazer muitos outros.

Diante desta pesquisa, é possível entender os clientes potenciais que a empresa trabalha e, assim, traçar estratégias de marketing para potencializar a MC Normalizações, tornando-a conhecida no mercado de trabalho, atraindo novos clientes e obtendo uma rentabilidade maior.

O Quadro 1, apresenta quais são os concorrentes diretos que a MC Normalizações possui, destacando as ameaças que eles representam e também as oportunidades que devem ser exploradas. Os dados apresentados foram pesquisados no Google e obtidos, também, do contato direto com os concorrentes.

\begin{tabular}{|c|c|c|}
\hline Nome & Oportunidade & Ameaça \\
\hline Idiomativo & Oportunidade de parceria. & $\begin{array}{l}\text { Pode oferecer o mesmo trabalho } \\
\text { por um preço melhor. }\end{array}$ \\
\hline Normalização Eficiente & $\begin{array}{l}\text { Oportunidade de parceria. } \\
\text { Oferece o serviço de revisão grama- } \\
\text { tical, porém não é feito por um } \\
\text { profissional especializado da área. }\end{array}$ & $\begin{array}{l}\text { Possui uma estrutura formalizada } \\
\text { que possibilita adquirir trabalhos } \\
\text { maiores. } \\
\text { Faz também a correção do portu- } \\
\text { guês, o que possibilita cobrar um } \\
\text { menor valor pelos dois serviços. }\end{array}$ \\
\hline Normalização Eficiente ABNT & $\begin{array}{l}\text { Possui apenas um preço fixo por } \\
\text { página, o que inviabiliza uma nego- } \\
\text { ciação. }\end{array}$ & Possui mestrado na área. \\
\hline Normalização Juliana & Oportunidade de parceria. & $\begin{array}{l}\text { Possuir maior relacionamento com } \\
\text { professores, o que lhe possibilita } \\
\text { maior indicações. }\end{array}$ \\
\hline $\begin{array}{l}\text { TCC Correção e Normalização de } \\
\text { Trabalhos Acadêmicos }\end{array}$ & $\begin{array}{l}\text { Possui pouco tempo no mercado e } \\
\text { pouca experiência. }\end{array}$ & Tem dedicação exclusiva. \\
\hline $\begin{array}{l}\text { Everaldo Nunes Formatação e } \\
\text { Normalização de Trabalhos Aca- } \\
\text { dêmicos }\end{array}$ & $\begin{array}{l}\text { Possui pouco tempo no mercado e } \\
\text { pouco tempo de dedicação. } \\
\text { Oferece o serviço de revisão grama- } \\
\text { tical, porém não é feito por um } \\
\text { profissional especializado da área. } \\
\text { Oportunidade de parceria. }\end{array}$ & $\begin{array}{l}\text { Por ser vinculada a um grupo de } \\
\text { empresas de grande porte de ensi- } \\
\text { no, os clientes do grupo podem } \\
\text { preferir seus serviços, pela facilida- } \\
\text { de de contato. }\end{array}$ \\
\hline Normalização & $\begin{array}{l}\text { Possibilidade de troca de informa- } \\
\text { ções. }\end{array}$ & $\begin{array}{l}\text { Por estar localizada em outro Esta- } \\
\text { do, os clientes locais podem preferir } \\
\text { seus serviços pela facilidade de } \\
\text { contato. }\end{array}$ \\
\hline $\begin{array}{l}\text { Normalização de Trabalhos Aca- } \\
\text { dêmicos }\end{array}$ & $\begin{array}{l}\text { Possibilidade de troca de informa- } \\
\text { ções. }\end{array}$ & $\begin{array}{l}\text { Por estar localizada em outro Esta- } \\
\text { do, os clientes locais podem preferir } \\
\text { seus serviços pela facilidade de } \\
\text { contato. }\end{array}$ \\
\hline
\end{tabular}

Fonte: Elaborado pelo autor (2017).

Com uma eficiente análise de concorrentes, é possível vislumbrar lacunas que existem na prestação de serviços das outras empresas e direcionar o produto para este nicho de mercado, ou até mesmo construir parcerias que sejam viáveis para ambos. Di- ante do exposto no Quadro 1, grande parte dos concorrentes podem se tornar amplos parceiros, com troca de informações de mercado e também ajuda terceirizada em períodos de pico. Por meio do quadro de ameaça, é possível estudar melhor a estrutu- 
ra de outras empresas e vislumbrar uma ainda melhor, que atenda de forma efetiva às expectativas dos clientes para a MC Normalizações.
Por fim, o Quadro 2 descreve os fornecedores que a MC Normalizações necessita para se manter, bem como o diferencial estratégico que os mesmos oferecem.

Quadro 2 - Análise de fornecedores

\begin{tabular}{|l|l|l|l|}
\hline \multicolumn{1}{|c|}{ Nome } & \multicolumn{1}{|c|}{ Contato } & \multicolumn{1}{c|}{ Produto Serviço } & \multicolumn{1}{c|}{ Política/relacionamento } \\
\hline Celesc & 0800480196 & Luz & Não tem. \\
\hline Net & 10621 & Internet & Não tem. \\
\hline Samantha & & Tradução & Oferece boa qualidade. \\
\hline Nivaldo & $(48) 3258-9808$ & Tradução & $\begin{array}{l}\text { Oferece um preço inferior ao mercado e um } \\
\text { prazo menor. }\end{array}$ \\
\hline Laís & (11) $99645-7361$ & Correção Ortográfica & $\begin{array}{l}\text { Oferece um preço inferior ao mercado e um } \\
\text { prazo menor. }\end{array}$ \\
\hline Matheus & (13) $99915-5312$ & Correção Ortográfica & $\begin{array}{l}\text { Oferece um preço inferior ao mercado e um } \\
\text { prazo menor. }\end{array}$ \\
\hline Eder & (48) $98424-7442$ & Correção Ortográfica & $\begin{array}{l}\text { Oferece um preço inferior ao mercado e um } \\
\text { prazo menor. }\end{array}$ \\
\hline
\end{tabular}

Fonte: dados da pesquisa (2017).

Ter bons fornecedores é essencial para o sucesso do negócio, pois são eles que dão suporte dos insumos necessários para conclusão dos serviços prestados pela empresa. Como pode-se vislumbrar no Quadro 2, a grande maioria dos fornecedores é pessoa física, o que facilita a proximidade para poder negociar preço e prazos de entrega dos insumos.

Saber quais são os concorrentes e seus fornecedores é algo que deve ser reavaliado constantemente para poder se posicionar no mercado e estar preparado a qualquer mudança que possa ocorrer.

\subsection{Estratégias de marketing}

Ao reunir as informações de clientes em potencial, concorrentes e fornecedores, é possível identificar suas principais necessidades e os melhores pontos que podem ser explorados a fim de impulsionar o interesse do consumidor. Isso contribui para o desenvolvimento de estratégias de marketing para a empresa se diferenciar no mercado. Inicialmente é preciso definir claramente qual vai ser o produto ofertado, o preço que será cobrado, os canais de distribuição previamente estabelecidos e a forma de promoção. Com estes preâmbulos, elaboram-se as propostas que devem ser implementadas para que a empresa possa ter sucesso e alcançar seus objetivos.
A empresa MC Normalizações atua no setor de prestação de serviços, oferecendo um atendimento personalizado na formatação e normalização de trabalhos acadêmicos, prestando serviços de confecção de slides para data show, gravação em PDF e digitação de Teses, Dissertações, Monografias, Relatórios de Estágio, Projetos e Trabalhos Acadêmicos. Atua fisicamente na grande Florianópolis, porém, por ser um serviço que pode ser prestado à distância, nada impede o atendimento de clientes das mais diversas localidades.

O produto ofertado está voltado para a população de todas as classes sociais, tendo em vista que, indiferente do poder aquisitivo, deve seguir um padrão das normas da ABNT para confeccionar trabalhos acadêmicos.

O preço para os serviços de tradução e revisão gramatical serão fixos, pois é um serviço terceirizado. $O$ valor da correção gramatical será fixado em reais por página e o valor da tradução, em centavos por palavra traduzida. Já o valor para formatação e normalização não será fixo, pois depende de uma análise mais robusta de como está a formatação do trabalho e da quantidade de páginas. O preço será baseado na qualidade dos serviços prestados e também no serviço qualificado, desenvolvido sempre por profissionais especialistas na área, sejam eles bibliotecários, tradutores e pessoas com forma- 
ção em letras. Os pagamentos serão feitos à vista ou no prazo de 30 dias. As condições de pagamento serão dinheiro, cheque ou depósito bancário.

A empresa tem suas instalações no município de Florianópolis. O bairro fica próximo ao centro, considerando que a cidade está em constante desenvolvimento, a localização contribui para a viabilidade do comércio, sendo próximo, também, da BR282 e dos polos industriais da região. Apesar de a empresa ter um ponto fixo, o atendimento principal é feito online, via e-mail ou Whats $A p p$ devido à localização variada dos clientes.

A publicidade será feita através de cartão de visita, e-mail, divulgação em sites, folder e cartazes nas Faculdades e Universidades.

\section{PROPOSTAS DE AÇÕES ESTRA- TÉGIAS DE MARKETING PARA MC NORMALIZAÇÕES}

Após realizar análise de alguns pontos da empresa e de seus clientes em potencial, é possível indicar algumas ações para implementar o plano de marketing proposto. da empresa.

a) Ação 1: Atualização e melhoria do site

O site da empresa está no ar desde 2008 e dispõe de logo, histórico, serviços prestados e contato, conforme visto na Figura 1 abaixo. Porém, não é utilizado como mecanismo de divulgação contínua, servindo apenas para busca de contato e identificação dos serviços que a empresa presta, não sendo atualizado constantemente.

Figura 1 - Site da empresa

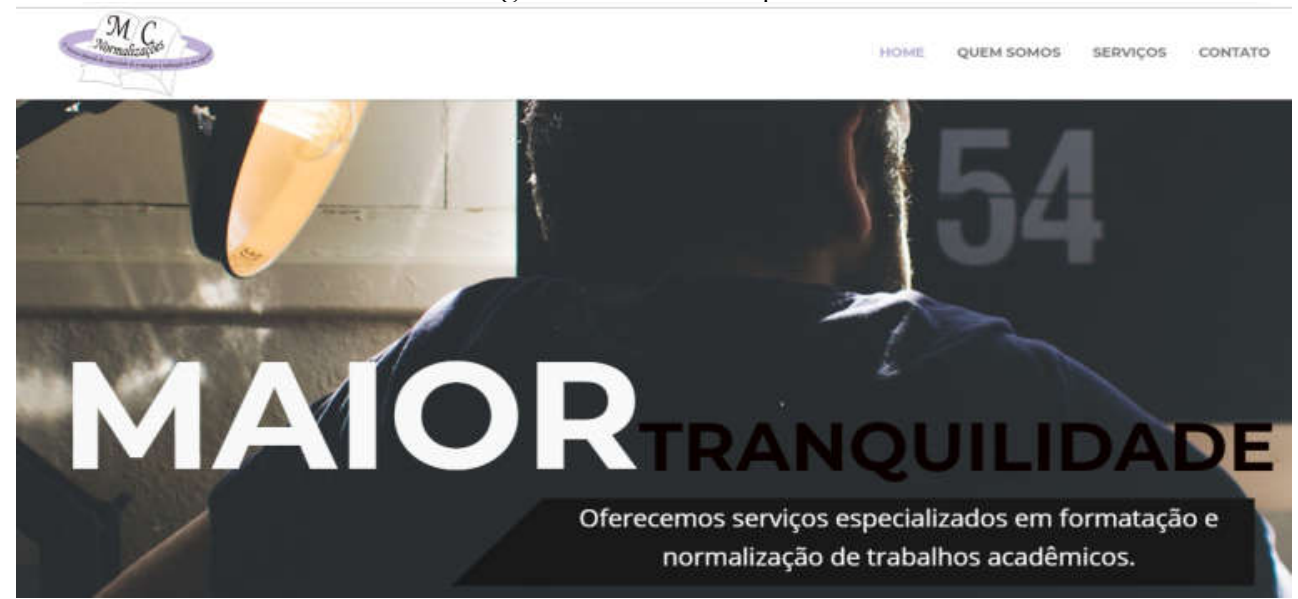

Fonte: elaborado pelo autor (2017).

O site deve ser atualizado a cada mês, ou no instante que surgir uma nova necessidade; deve conter também as formas de pagamento e o horário de funcionamento da empresa. Para que o site possa servir como cartão de visita da empresa, deve ser mais completo e ter um designer moderno, abarcando informações que muitos clientes exigem e buscam como a missão, a visão e os valores da empresa. Assim, na próxima ação, recomenda-se a criação desses mecanismos para que o cliente tenha um conhecimento mais amplo da empresa que está contratando. b) Ação 2: Criação da missão, visão e os valores da empresa.

Missão: Promover soluções digitais para trabalhos acadêmicos por meio de consultoria personalizada e com profissionais especializados que atendam às expectativas de nossos clientes.

$V$ isão: Ser lembrada como uma empresa diferenciada e de qualidade para soluções digitais e padronização de trabalhos acadêmicos na grande Florianópolis.

Valores: humano;

- flexibilidade e valorização do ser

- responsabilidade, ética e confiança; 
- inovação e busca de excelência;

- responsabilidade social e ambiental.

c) Ação 3: Criar um banco de dados.

Criar um banco de dados com informações de clientes que contemple o Whats App, a data de aniversário e o e-mail, assim é possível fazer campanhas publicitárias por mala direta no e-mail, enviar felicitações em datas comemorativas, oferecer promoções, descontos e formas de pagamento diferenciado. Esses procedimentos ajudam a divulgar a empresa e também a fidelizar os clientes. zes e folders.

d) Ação 4: Divulgar a empresa via carta-

A cada dois meses uma pessoa da equipe da empresa deverá ir até as universidades e colocar cartazes com informações dos serviços e do contato da empresa. Nesta mesma oportunidade, poderá distribuir folders para os acadêmicos. Este tipo de mídia é focado no público alvo e possui gastos financeiros pequenos, o que viabiliza sua execução pela perspectiva de retorno.

\section{e) Ação 5: Divulgar a empresa via site.}

De acordo com a pesquisa de clientela, $52 \%$ das pessoas buscariam informações de empresas que prestam serviços da ABNT na Internet; diante destes dados, é fundamental a divulgação em sites gratuitos como OLX, Bom Negócio e Vivanúncios. Além disso, recomenda-se a divulgação no site pago Guia Floripa, por ser influente e utilizado na região.

\section{f) Ação 6: Desenvolver promoçoes.}

Criar promoções em períodos de baixa procura para atrair novos clientes. Poderá ser dado $20 \%$ de descontos nos serviços prestados entre os meses de março a junho, setembro e outubro. Também poderá ser oferecido o mesmo desconto para quem já for cliente, ou indicar um amigo, incentivando a divulgação da empresa para os amigos.

g) Ação 7: Criar banco de dados dos tercei-
riz̧ados.
Criar um banco de dados com os parceiros fixos e possíveis empresas e pessoas aptas a fazer serviços terceirizados de tradução, português e da própria ABNT, caso a empresa não dê conta de suprir a demanda. Assim, em caso de emergência, a empresa poderia contatar facilmente seus parceiros.

b) Ação 8: Melhoria na qualidade de atendimento e no serviço prestado.

A melhoria no atendimento está atrelada à identificação da satisfação e desejos dos clientes, pois, um cliente insatisfeito com o atendimento é capaz de recorrer à concorrência. Para que tal fato não ocorra, a empresa precisa oferecer treinamentos à equipe a fim de motivá-los a buscar melhorias na empresa, monitorando o nível de satisfação dos clientes. Esse treinamento deve se estender a seus parceiros, de modo que a qualidade se mantenha mesmo na terceirização de algum serviço.

\section{CONSIDERAÇÕES FINAIS}

A fidelização de clientes tem adquirido relevância cada vez maior no âmbito das empresas. Além de voltar a consumir os produtos e serviços, o cliente também atrai novos clientes de sua rede de relacionamento, possibilitando o crescimento contínuo da empresa. As ações aqui descritas no plano de marketing, apesar de não estarem em vigor ainda, pretendem alcançar um número considerável de novos clientes. Serão aplicadas ideias simples de marketing, mas que possibilitem uma maior visibilidade da empresa e atinjam diretamente o cliente potencial.

Diante desse mercado de trabalho volátil e com grandes possibilidades, vence a empresa que for mais flexível quanto às suas atividades e a que consegue se adaptar mais facilmente, no entanto, sempre seguindo sua missão. Ou seja, seguir a missão é inclusive dar passos que sejam conscientes e planejados, pois, se assim não for, o empresário pode estar colocando a empresa em risco.

Depois de realizar a pesquisa com a clientela e concluir o plano de marketing, percebe-se ainda mais sua importância e seus 
benefícios para qualquer empresa. Através do marketing e do estudo de mercado, o empreendedor consegue desenhar perfis de planos de ação favoráveis com o momento do negócio, interligando o marketing de relacionamento com o Web marketing de modo a agregar valor aos produtos e serviços ofertados, tornando-os mais conhecidos ao público alvo.
O diagnóstico efetuado por meio da pesquisa foi fundamental para que a empresa pudesse traçar as ações e estratégias de marketing e assim almejar um crescimento maior, com segurança e responsabilidade, sabendo onde quer chegar e como deve fazer isso.

\title{
DIAGNOSIS AND MARKETING PLAN FOR A COMPANY OF STANDARDIZATION OF ACADEMIC WORKS
}

\begin{abstract}
The market for service provision in the in the area of normalization of academic work is not very well known, with few companies and people specialized in the area. Yet, in recent years, with more academics joining the universities and lack of time for dedication to this activity, the search for this type of service has increased. In this scenario, companies must devise marketing strategies with the purpose of being known and being an option of biring clients. The study was developed in the company MC Normalizations, provider of formatting and standardization services of academic works according to ABNT standards. A marketing plan was developed with the purpose of increasing the company market share, thus retaining new customers. In order to know the potential customers, a questionnaire was carried out to identify the main needs and the financial disposition to pay for this type of service. The diagnosis is that the company does not have a consolidated Marketing department but practices some Marketing actions with the clients. This marketing plan will serve as a basis for new actions, belping the company to achieve its mission and vision. In view of these results, it can be concluded that the focus of marketing actions should aim the dissemination via Internet, as it is where customers are looking for this service, and based on quality, which will help in divulging to college colleagues and friends.
\end{abstract}

Keywords

Marketing plan. Academic work. ABNT. Information Management-Marketing. Artigo recebido em 13/04/2017 e aceito para publicação em 11/12/2018

\section{REFERÊNCIAS}

AMA - American Marketing Association. Marketing. Disponível em: https://www.ama.org/AboutAMA/Pages/ Definition-of-Marketing.aspx. Acesso em: 28 nov. 2018.

AMARAL, S. A.Marketing da informação: abordagem inovadorapara entender o mercado e o negócio da informação.

Ciência da Informação, Brasília, DF, v. 40 n. 1, p.85-98, jan./abr., 2011.

ASSIS, G. F. E-Market: o mercado automatizado e ele tronicament e integrado. Revista da FAE, Curitiba, v. 4, n. 1, p. 69 75, jan./abr. 2001. Disponível em: https://revistafae.fae.edu/revistafae/article/ view/456/351. Acesso em: 28 nov. 2018. BRASIL. Ministério da Educação. Mulheres são maioria no ingresso e na conclusão de cursos superiores: no último ano do decênio, do total aproximado de 6 milhões de matrículas, 3,4 milhões foram de mulheres, contra 2,7 milhões do sexo oposto.

Governo do Brasil, 8 mar. 2015. Disponível em:

http://www.brasil.gov.br/noticias/educacao -e-ciencia/2015/03/mulheres-sao-maioriano-ingresso-e-na-conclusao-de-cursossuperiores. Acesso em: 28 nov. 2018.

CHURCHILL, JR. G. A., PETER, J. P. Marketing: criando valor para os clientes. 2. ed. São Paulo: Saraiva, 2005.

DIAS, A. R. WebShoppers: o ciclo de compra online em 2016. Allin, 6 set. 2016. Disponível em: https://allin.com.br/news/webshoppers-ociclo-de-compra-online-em-2016/. Acesso em: 28 nov. 2018. 
DIAS, S. R. (Coord.). Gestão de marketing. São Paulo: Saraiva. 2007.

GRIESINGER, D. Número de estudantes no ensino superior aumenta; maioria ainda é branca e rica: Em 2014, eles somavam $58,5 \%$ do total de estudantes de 18 a 24 anos, 25. Agência Brasil, 4 dez. 2015. Disponível em: http://agenciabrasil.ebc.com.br/geral/notici a/2015-12/ensino-superior-avanca-25pontos-percentuais-entre-jovens-estudantesem-10. Acesso em: 28 nov. 2018.

KEEGAN, W. J.; GREEN, M. C. Princípios de Marketing Global. São Paulo: Saraiva, 2003.

KOTLER, P. Administração de marketing: a edição do novo milênio. 10. ed. São Paulo: Prentice-Hall, 2000.

KOTLER, P.; ARMSTRONG, G. Princípios de Marketing. 9. ed. São Paulo: Prentice Hall do Brasil, 2003.

KOTLER, P.; KELLER, K. L. Administração de Marketing. 12. ed. São Paulo: Pearson Prentice Hall, 2006.

LAS CASAS, A. L. Marketing: conceitos, exercícios e casos. 8. ed. São Paulo, SP: Atlas, 2009.

LAS CASAS, A. L. Plano de marketing para micro e pequena empresa. São Paulo: Atlas, 2006.

LAS CASAS, A. L. Técnicas de vendas: como vender e obter bons resultados. 4. ed. São Paulo, SP: Atlas, 2011.

LONGENECKER, J. G. et al. Administração de pequenas empresas. São Paulo, SP: Cengage Learning, 2015.

LOVELOCK, C.; WRIGHT, L. Serviços: Marketing e Gestão. São

Paulo: Saraiva, 2001.
MARICATO, P. Marketing para bares e restaurantes. Rio de Janeiro: SENAC, 2005.

MORENO, A. C.; FAJARDO, V. Número de matrículas no ensino superior cresce $81 \%$ em dez anos: Entre 2003 e 2012, número cresceu de 3,8 milhões para 7 milhões. Inep divulgou na quarta dados do Censo da Educação Superior de 2012. G1, 31 out. 2013. Disponível em: http://g1.globo.com/educacao/noticia/201 3/10/numero-de-matriculas-no-ensinosuperior-cresce-81-em-dez-anos.html. Acesso em: 28 nov. 2018.

SANTANNA, A. Propaganda: teoria, técnica e pratica. São Paulo: Editora Pioneira. 2001.

SARAIVA, A. Descubra como conquistar o público jovem. Jornal Estadão. 2012. Disponível em: http://pme.estadao.com.br/noticias/noticia s, descubra-como-conquistar-o-publicojovem,1687,0.htm. Acesso em: 28 nov. 2018.

SEBRAE - Serviço Brasileiro de Apoio às Micro e Pequenas Empresas. Sobrevivência das empresas no Brasil. 2016. Disponível em:

https://www.sebrae.com.br/Sebrae/Portal $\% 20$ Sebrae/Anexos/sobrevivencia-dasempresas-no-brasil-102016.pdf. Acesso em: 28 nov. 2018.

WESTWOOD, J. O plano de marketing. 3. ed. São Paulo: M. books, 2007.

ZINKOTA, M. R. et al. Marketing: as melhores práticas. 3. ed. Porto Alegre: Bookmam, 2001.

ZUINI, P. Como atrair o público jovem para sua empresa? Revista Exame. 2011. Disponível em: https://exame.abril.com.br/pme/comoatrair-o-publico-jovem-para-sua-empresa/. Acesso em: 28 nov. 2018. 